\title{
Digitally Controlled Converter with Dynamic Change of Control Law and Power Throughput
}

Nesgaard, Carsten; Andersen, Michael Andreas E.; Nielsen, Nils

Published in:

2003 IEEE 34th Annual Power Electronics Specialists Conference

Publication date:

2003

Document Version

Publisher's PDF, also known as Version of record

Link back to DTU Orbit

Citation (APA):

Nesgaard, C., Andersen, M. A. E., \& Nielsen, N. (2003). Digitally Controlled Converter with Dynamic Change of Control Law and Power Throughput. In 2003 IEEE 34th Annual Power Electronics Specialists Conference (Vol. 3, pp. 1163-1168). IEEE.

\section{General rights}

Copyright and moral rights for the publications made accessible in the public portal are retained by the authors and/or other copyright owners and it is a condition of accessing publications that users recognise and abide by the legal requirements associated with these rights.

- Users may download and print one copy of any publication from the public portal for the purpose of private study or research.

- You may not further distribute the material or use it for any profit-making activity or commercial gain

- You may freely distribute the URL identifying the publication in the public portal 


\section{Digitally Controlled Converter with Dynamic Change of Control Law and Power Throughput}

\author{
Carsten Nesgaard \\ Technical University of Denmark \\ DK-2800 Kongens Lyngby \\ E-mail: cn@oersted.dtu.dk
}

\author{
Michael A. E. Andersen \\ Technical University of Denmark \\ DK-2800 Kongens Lyngby \\ E-mail: ma@oersted.dtu.dk
}

\author{
Nils Nielsen \\ Technical University of Denmark \\ DK-2800 Kongens Lyngby \\ E-mail: nni@oersted.dtu.dk
}

\begin{abstract}
With the continuous development of faster and cheaper microprocessors the field of applications for digital control is constantly expanding. Based on this trend the paper at hand describes the analysis and implementation of multiple control laws within the same controller. Also, implemented within the control algorithm is a thermal monitoring scheme used for assessment of safe converter power throughput. An added benefit of this thermal monitoring is the possibility of software implemented analytic redundancy, which improves system fault resilience. Finally, reliability issues concerning the substitution of analog controllers with their digital counterparts are considered.

The outline of the paper is divided into two segments - the first being an experimental analysis of the timing behavior by means of code optimization - the second being an examination of the dynamics of incorporating two control laws using multiple control parameters.
\end{abstract}

\section{INTRODUCTION}

The continuous evolution of still faster processors at ever increasing performance levels provides a basis for application areas ranging from monitoring and supervisory circuitry to high speed redundancy control of complex power systems [1]. Furthermore, these benefits come at ever lower costs, thus making digital control an attractive alternative to the traditional analog control circuits found in most power electronics applications today.

The very fact that power electronics has benefited greatly from the continuing development in microprocessor technology is seen by the numerous papers and articles describing among other things the implementation of promising new control schemes [2].

This paper examines the possibilities of implementing two different control laws within the same low cost controller. The change in control law is dynamic and is based on the continuous measurement of key parameters. The control laws between which the microcontroller alters are a standard pulse width modulation (PWM) control law and the simpler pulse skipping (PS) control law. Since switching losses are dominant at no and light loads in most converter topologies the controller applies the PS control law when operated in this region. At heavier and full load the total converter losses are a combination of switching losses and conduction losses for various converter components. Therefore when operated in this region the PWM control law is applied to the converter.

Also, included in the converter control algorithm is a continuous measurement of converter worst-case temperature for assessment of converter power throughput capability. It is well known that internal operating temperature depend on ambient temperature, power losses within the converter and the thermal capabilities of the heatsinks used. Therefore it is of vital importance for the continuous supply of power that the worst-case temperature is measured on a regular basis. Based on loss analysis the worst-case temperature for the test converter is found at the switching transistor for which reason the temperature-monitoring device is mounted at the transistor case. A description of the thermal aspects as well as the dual implementation of the control algorithm is provided in section 'IV. CONTROL ALGORITHM AND MONITORING',

When substituting analog controllers with digital equivalents reliability issues must be considered. This topic is discussed in section 'VI. RELIABILITY'.

Following the reliability discussion section "VII. EXPERIMENTAL RESULTS' provides measurements verifying successful implementation of the proposed control algorithm.

Finally, section 'VIII. FURTHER WORK' gives a description of ideas for further work within the field of digital controllers in $\mathrm{DC} / \mathrm{DC}$ converter applications.

\section{THE CONTROLLER}

The controller used in the test setup is the 8-bit RISC PIC16F877 microcontroller from Microchip [3]. It's core features relevant to the application at hand include:

$8 \mathrm{~K}$ 14-bit word flash memory
$256 \mathrm{E}^{2} \mathrm{PROM}$ data memory
10 -bit PWM module
8 channel 10 -bit $\mathrm{A} / \mathrm{D}$ converter
Single cycle operations
$20 \mathrm{MHz}$ clock frequency

Thus, making the PIC16F877 ideal for controlling a DC/DC converter. This fact combined with the low power consumption and high-quality development tools provided by the device manufacturer made it the microcontroller of choice. 
Based on equations found in the device datasheet on calculating the acquisition time for a single $\mathrm{A} / \mathrm{D}$ conversion, an average value of $20.8 \mu \mathrm{s}$ for each analog parameter conversion can be established. Due to the low bandwidth that results from this rather long acquisition time, converter control and shift in control law based primarily on periodic sampled analog parameters are to be avoided. For this reason a trade-off between execution speed, precision, complexity and cost is therefore inevitable. If the acquisition time of the A/D converter within the microcontroller cannot be accepted due to lack of execution speed an external A/D conversion circuitry can be added. Unfortunately this adds to both cost and complexity of the overall system. Since the focal point in this presentation is an examination of the PIC microcontroller capabilities in converter control no external circuitry is added.

\section{IIl. TEST CIRCUIT}

The test circuit is comprised of a $5 \mathrm{~W}$ buck converter designed for continuous conduction mode, a number of measurement circuits and a PIC microcontroller clocked at 20 MHz. A graphical representation of the test circuit is seen in Fig. 1.

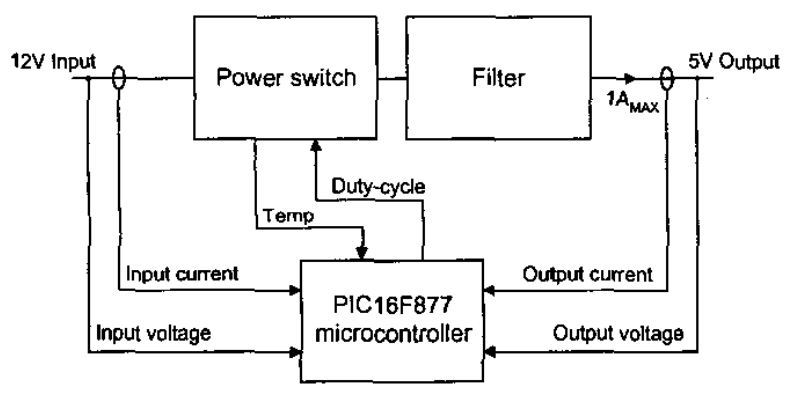

Fig. 1 : Test setup

The buck converter, which is represented by the blocks 'Power switch' and 'Filter', is comprised of a $200 \mu \mathrm{H}$ inductor, a $1 \mathrm{mF}$ output filter capacitor, a 1 N5811 schottky free wheeling diode and a IRF9530 power MOSFET. Voltage sensing is achieved by utilization of a simple voltage divider while current sensing is achieved by means of a sensing resistor. Utilization of these simple techniques has the disadvantage of resulting in lower overall converter efficiency than otherwise obtainable with more sophisticated techniques. However, the focal point in this presentation remains clear regardless which technique is used.

Finally, the temperature-sensing device is a 2-wire digital thermometer from Dallas Semiconductors/Maxim. It is equipped with an $\mathrm{I}^{2} \mathrm{C}$ interface suitable for communication with the microcontroller.

\section{CONTROL ALGORITHM AND MONITORING}

The control algorithm and monitoring functions are implemented using the development software MPLAB from Microchip. Although MPLAB allows for generation of source code using standard $\mathrm{C}$ the source code for the control algorithm implemented in the test converter is written in assembler due to the optimized compilation that results.

Examination of source code implementation via subroutines to which the main program guides the instruction pointer revealed that the sample timing depended on the number of as well as which instructions were executed. Since this is an unacceptable situation in a DC/DC converter the faster and more precise code execution obtained by applying an interrupt based program structure for control parameter sampling is implemented.

The determination of which control law to apply at any given time is based on a set of measurements of the input current, input voltage, output current and output voltage. Of these four parameters that all can be identified in Fig. 1 the measurement of the output voltage is the most important parameter since the generation of a proper Duty-cycle depends solely of this particular parameter. The change in control law from PWM to PS occurs when the power level decreases below $1.5 \mathrm{~W}$ (equal to $300 \mathrm{~mA}$ ) while the change in control law from PS to PWM occurs when the power level increases above $2 \mathrm{~W}$ (equal to $400 \mathrm{~mA}$ ). Thus, the control algorithm incorporates hysteresis, which prevents a state of oscillation between the two control laws. Detailed calculations concerning the optimum operating point where the changes in control law should occur is found to be at $1.85 \mathrm{~W}$ (equal to $370 \mathrm{~mA}$ ). However, using this single point of the operating curve as a mark for control law changes results in oscillatory behavior, when slightly variable load currents around $370 \mathrm{~mA}$ is supplied by the converter. This oscillatory behavior results in increased high frequency noise and deteriorated dynamic converter performance - thus justifying the use of hysteresis.

Initially the PWM control law was implemented in realtime in which calculations are performed continuously based on the measured output voltage. However, analysis of the program execution speed revealed that in order to maintain an acceptable sampling frequency a different implementation technique had to be used. Under normal operating conditions it is possible to predict the behavior of the converter and therefore in an analytic way calculate the Duty-cycle needed for proper operation. This analytic fact can be used to generate a look-up table containing ail the information needed for continuous converter operation within the specified limits. From the microcontroller datasheet it can be seen that accessing the program memory can be achieved in 16 cycles, which equates to $4 \mu \mathrm{s}$. Of the available $8 \mathrm{~K}$ program memory only a small segment is used for the actual control software, thus leaving plenty of memory available for other purposes. Implementation of the proposed look-up table 
is simplified by means of a small C program that generates an assembler file containing the numerical values. Once the entire set of assembler files are compiled the look-up table is placed in memory along with the control algorithm. The optimized code execution caused by the look-up table results in a switching frequency of $77 \mathrm{kHz}$ and a sampling frequency of $10 \mathrm{kHz}$ when operated in PWM mode. Due to asymmetrical skipping of pulses in PS mode the switching frequency is no longer fixed. However, the sample frequency remain unchanged.

When operated outside the specified conditions the generation of the Duty-cycle is performed in real-time lowering the sample frequency to $3 \mathrm{kHz}$. This rather low sample frequency would under normal conditions be unacceptable, but instead of simply shutting down the converter in case of abnormal operating conditions the proposed control algorithm provides a continuous supply of power although at a degraded level.

It is well known that converter power throughput is a function of temperature. Manufactures of commercially available converters most often specify the power a given converter can deliver under certain operating conditions. Thus, making the user responsible for proper cooling and/or control of ambient temperature. Permanent damage to the converter is likely to occur if the specified values are exceeded. As an extra safety precaution many modern converters have thermal shutdown capabilities, which shuts down the converter as the maximum temperature is reached. Since thermal shutdown capability provides no or little warning before the protective circuitry shuts down the converter, the proposed control algorithm includes a dynamic change of power throughput as a function of temperature. This allows for active temperature management, since at any given time the temperature can be related to the losses within the converter. Keeping a converter running at maximum power throughput during a temperature rise eventually causes the thermal protection to shut down the converter. In a standalone configuration the dynamic change in power throughput as a function of temperature provides little or no advantages over the thermal shutdown protection. However, in load priority applications or in redundant configurations the loads with the lowest priority will simply be disconnected from the converter and thereby improve the probability of a continuous supply of power to the critical loads.

\section{EFFICIENCY IMPROVEMENT}

Converter efficiency curves most often have a shape similar to that shown in Fig. 2. This is due to the distribution of conduction losses and switching losses. Mentioned in section 'I INTRODUCTION' the switching losses are dominant at light loads, thus causing the efficiency in this region of the operating range to decrease quite dramatically. Fig. 2 shows the test converter efficiency when operated in PWM mode.

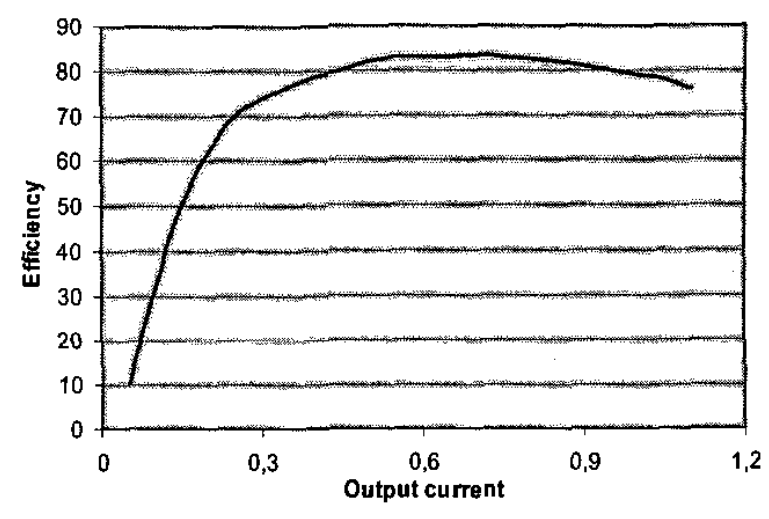

Fig. 2 : Efficiency of PWM control

Applying the PS control law it is theoretically possible to improve the overall efficiency at light loads. Indeed, section 'VII. EXPERIMENTAL RESULTS' shows that this is the case.

\section{RELIABILITY}

While the continuous development in microprocessor technology makes it attractive to replace analog circuitry with digital equivalents the pros and cons in each case should be considered very carefully. While analog controllers have advantages of high bandwidth, no need for $A / D$ conversion, high resolution and fast response to changes in fixed control parameters their digital counterparts have the advantage of being able to respond not only to changes in the fixed control parameters but also to changes in variables within the converter. Furthermore digital controllers have the ability to respond intelligently to the loss of fixed control parameters. By means of analytic behavior of converter operation the lost control parameter can often be deduced from the control parameters available. Although, different from the technique used in this paper one such analytic approach in determining immeasurable parameters is given in [4].

Based on the continuous measurement of input power, output power and system temperature the proposed control algorithm improves system reliability by means of a technique known as analytical redundancy. Analytical redundancy is the concept of determining a parameter based on measurements of different variables. Thus, establishing a configuration of variables suitable for describing any one of the $N$ variables in case one measurement is lost. This technique compensates for some of the loss in system reliability when interchanging the analog controller with its digital counterpart. An exact number of the loss in reliability due to this interchange can be found using the data given in 'Military Handbook 217' concerning reliability prediction of electronic equipment: 
A commercially available analog controller in a 16pin DIP package designed for ground-based equipment has a Mean Time To Failure (MTTF) of 1.7 million years.

An 8-bit PIC microcontroller in a 40-pin DIP package designed for ground-based equipment has a Mean Time To Failure (MTTF) of 0.46 million years.

It is seen that the MTTF decreases by a factor of 3.7 when replacing the analog controller unit with its digital counterpart. Furthermore, the reliability of the software implemented in the digital controller has to be considered. Combining these reliability issues one finds that although analytical redundancy and other complex techniques can be applied in a digital controller the analog controller still provides the optimum reliability in simple converter control.

Having mentioned the drawbacks of digital control, one should note that the increase in 'intelligence' in converter control open the door to new reliability improvements not possible with analog controllers.

Although the response to a temperature change is much slower than to a voltage or current change analytical redundancy using the temperature in conjunction with other variables can be applied. Suppose the circuit for measuring output current fails. Under normal circumstances this would imply that the efficiency of the converter is zero and thus the converter has failed. By applying analytical redundancy the controller is able to determine whether the converter has failed or not. The test circuit in this presentation applies analytical redundancy by relating the converter power throughput to the temperature. On the assumption the previously mentioned fault occurs the controller would sustain the power throughput as long as the current limit is not exceeded. The constant monitoring of the system temperature can hereon after be used as a means of deciding which control law to apply.

\section{EXPERIMENTAL RESULTS}

This section provides measurements for the test converter under consideration.

As verification of proper Duty-cycle generation in both control modes the first set of measurements is the MOSFET gate voltage.

The MOSFET gate voltage in PWM mode is shown in Fig. 3 It can be seen that the switching frequency of the test converter is $76.9 \mathrm{kHz}$, which is very close to the expected 77 kHz.

The very narrow MOSFET gate voltage pulses in PS mode are shown in Fig. 4. Since the pulse skipping is asymmetrical and is solely based on the load no fixed switching frequency is used.

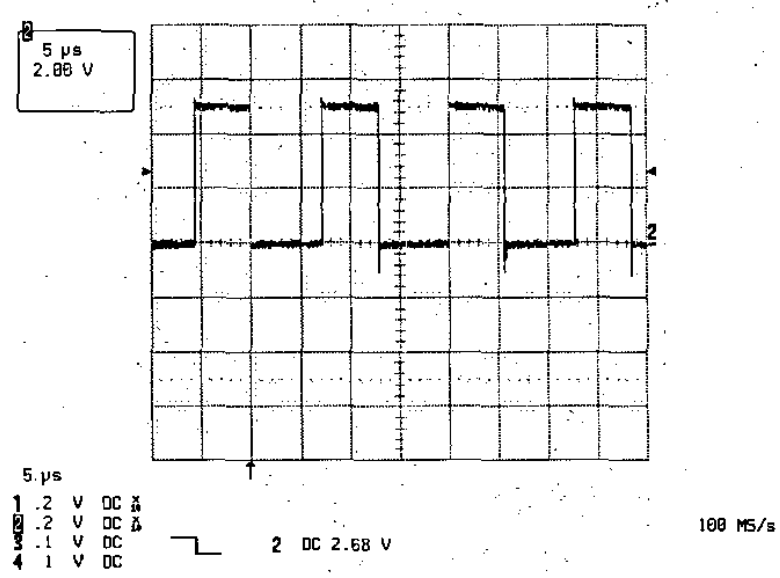

Fig. 3 : Converter operating in PWM mode

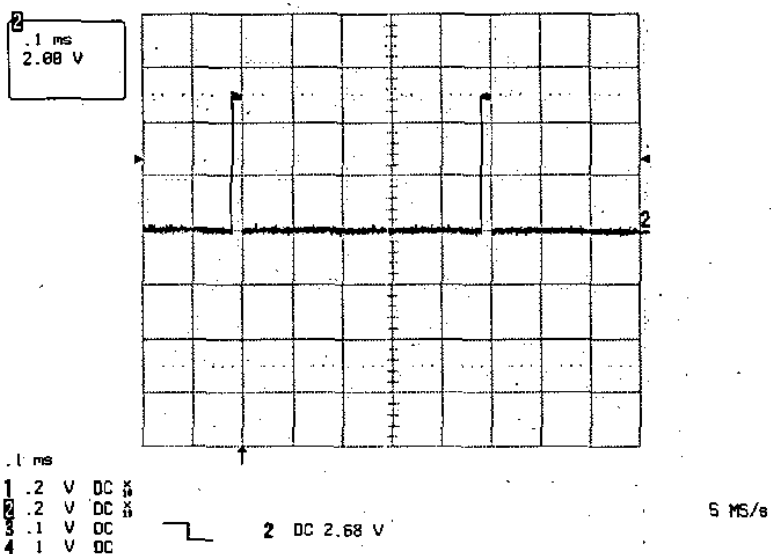

Fig. 4 : Converter operating in PS mode

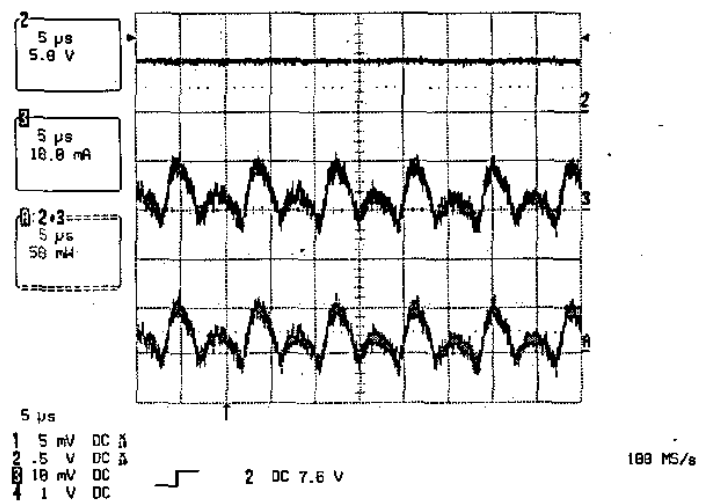

Fig. 5 : Control circuit power consumption 
In Fig. 5 the rather low current drawn by the digital controller and the temperature sensing device can be seen. Low power consumption for the control circuitry adds to the list of advantages of using digital controllers in converter applications. Replacing the digital controller of the test converter with an analog controller causes the total control circuitry power consumption to double.

Fig. 6 shows the increase in converter efficiency at lighter loads (purple curve). The point where the blue and purple curves intersect is the optimum point of change in control law from PWM to PS and vice versa. However, as mentioned previously this can lead to oscillatory converter behavior with very undesirably consequences as a result. Therefore the implemented control algorithm incorporates hysteresis. An enhanced view of this hysteresis loop can be seen in Fig. 7.

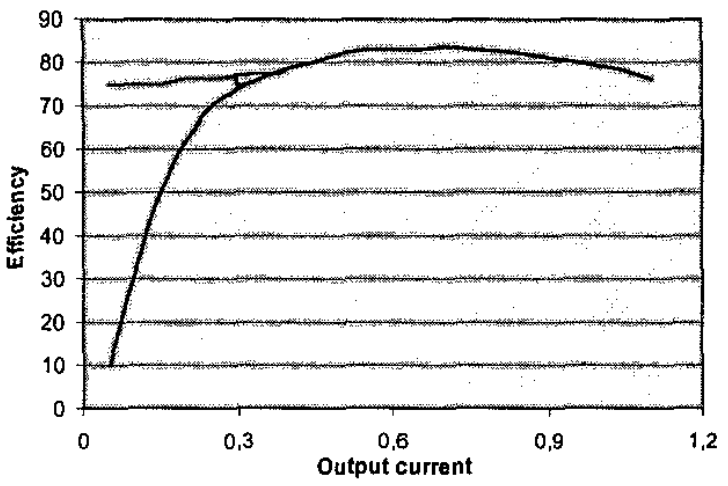

Fig. 6 : Efficiency of PS and PWM control

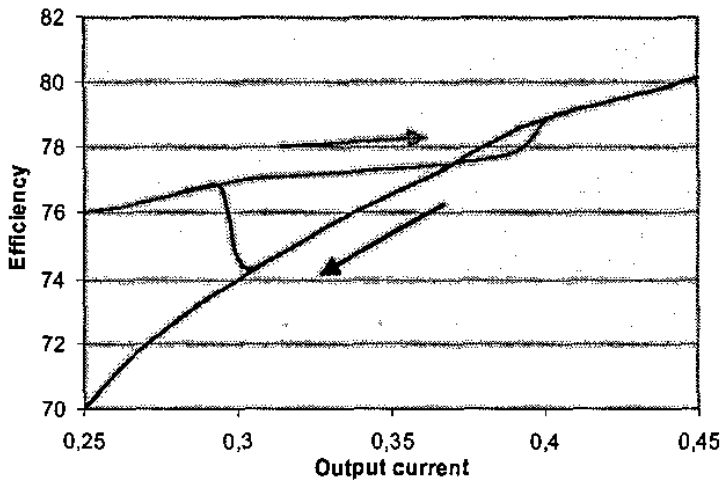

Fig. 7 : Enhanced view of hysteresis loop

VIII. FURTHER WORK

The field of digital control of converters by means of lowcost microcontrollers provides many features not mentioned in this presentation. Further work should address topics such as fault management implementations methods in low-cost microcontrollers as well as fault prediction schemes imbedded in the converter control algorithms.

Currently a formalized analysis of implementation schemes of analytical redundancy in standard converter topologies is being carried out. The foundation for this work is an establishment of converter topology connection matrices in combination with fault propagation analysis. Redrawing the test converter in Fig. 1 in accordance with the graph theoretical principles the following oriented connection graph can be established.

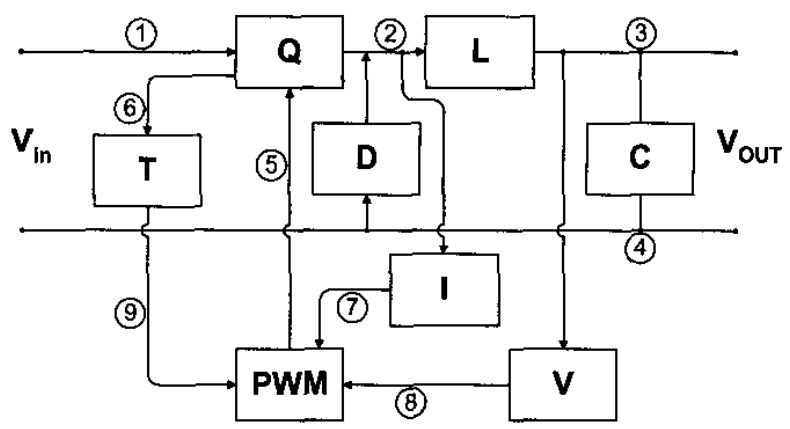

Fig. 8 : Buck test converter connection graph

Analyzing the connection graph in Fig. 8 using the graph theoretical approach the following connection matrix can be established:

TABLE 1 : BUCK CONNECTION MATRIX

\begin{tabular}{c|c|c|c|c|c|c|c|c|c}
\hline & $\mathbf{1}$ & $\mathbf{2}$ & $\mathbf{3}$ & $\mathbf{4}$ & $\mathbf{5}$ & $\mathbf{6}$ & $\mathbf{7}$ & $\mathbf{8}$ & $\mathbf{9}$ \\
\hline $\mathbf{1}$ & 0 & Q & 0 & 0 & 0 & Q & 0 & 0 & 0 \\
\hline $\mathbf{2}$ & 0 & 0 & L & 0 & 0 & Q & I & 0 & 0 \\
\hline $\mathbf{3}$ & 0 & 0 & 0 & $\mathrm{C}$ & 0 & 0 & 0 & $\mathrm{~V}$ & 0 \\
\hline $\mathbf{4}$ & 0 & $\mathrm{D}$ & $\mathrm{C}$ & 0 & 0 & 0 & 0 & 0 & 0 \\
\hline $\mathbf{5}$ & 0 & $\mathrm{Q}$ & 0 & 0 & 0 & $\mathrm{Q}$ & 0 & 0 & 0 \\
\hline $\mathbf{6}$ & 0 & 0 & 0 & 0 & 0 & 0 & 0 & 0 & T \\
\hline $\mathbf{7}$ & 0 & 0 & 0 & 0 & $\mathrm{P}$ & 0 & 0 & 0 & 0 \\
\hline $\mathbf{8}$ & 0 & 0 & 0 & 0 & $\mathrm{P}$ & 0 & 0 & 0 & 0 \\
\hline $\mathbf{9}$ & 0 & 0 & 0 & 0 & P & 0 & 0 & 0 & 0
\end{tabular}

where $\mathrm{P}$ is short for the PWM controller, $\mathrm{V}$ is short for the voltage sensing circuitry and $I$ is short for the current sensing circuitry. The remaining matrix entries $\mathrm{Q}, \mathrm{L}, \mathrm{D}, \mathrm{C}$ and $\mathrm{T}$ identify the switching transistor, the inductor, the free wheeling diode, the output capacitor and the temperature sensor respectively. Since the information of interest in the application at hand is the lines interconnecting the converter nodes, it can be seen that the input voltage and input current are not included. Had the converter in Fig. 8 been implemented with for instance voltage feedforward the input 
voltage would be part of the Duty cycle generation, thus being an entry of the matrix in TABLE 1 .

With reference to TABLE 1 it can be seen that the Duty cycle (5) for controlling the switch is generated based on 3 different parameters. Establishing the theoretical relations between these converter parameters as well as considering the measurement of these same parameters from an operational point of view it is possible to continue the converter operation in case of certain faults - although at a deteriorated level. This increases overall system reliability as described in section "VI. RELIABILITY'. In other words the current research is expected to provide a theoretical framework and model for future implementations of analytic redundancy in single path converters. In this context single path converters are characterized as converters comprised of a single electrical connection between input and output.

\section{CONCLUSION}

This paper has examined the converter control capabilities of a PIC microcontroller. The proposed control scheme based on efficiency improvement at light loads has shown that implementation of multiple control laws is indeed within the timing limits of a standard low-cost microcontroller. Furthermore, it has been shown that temperature measurement allows for implementation of analytical redundancy, which improves system fault resilience although true hardware fault tolerance can only be achieved in redundant converter configurations. Also, it has been shown how a measurement of transistor temperature can be used in protecting the converter from overheating by constantly adjusting the converter power throughput.

A short description of further work within the field of digital controllers has also been given and the current research concerning a formalization of the mathematical analysis of analytical redundancy optimization was presented.

\section{ACKNOWLEDGEMENT}

The author would like to thank Alcatel Space Denmark for sponsoring this work and Rune Moller Barnkob for implementing and testing the control algorithm as well as the monitoring functions.

\section{REFERENCES}

[1] C. Nesgaard, 'An array-based study of increased system lifetime probability', Proceedings IEEE-APEC 2003

[2] C. Rech, H. Pinheiro, H. A. Gründling, H. L. Hey, J. R. Pinheiro, 'Analysis and Design of a Repetitive PredictivePID Controller for PWM Inverters', Proceedings IEEEPESC 2001

[3] Microchip, 'PIC16F87x Data Sheet'

[4] D. Y. Qiu, S. C. Yip, Henry S. H. Chung, and S. Y. R. Hui, 'On the Use of Current Sensors for Control of Power Converters', Proceedings IEEE-PESC 2001

[5] Military Handbook 217, 'Reliability prediction of electronic equipment'

[6] I. Celanovic, I. Milosavljevic, D. Boroyevich, R. Cooley, J. Guo, 'A New Distributed Digital Controller for the Next Generation of Power Electronics Building Blocks', Proceedings IEEE-APEC 2000 